\title{
AVEc Proust, O EL Deseo de UNA TEORÍA DEL DESEO
}

\author{
Carlos Surghi \\ Universidad Nacional de Córdoba \\ Consejo Nacional de Investigaciones Científicas y Técnicas \\ carlossurghi@yahoo.com.ar
}

Resumen: El presente trabajo analiza de qué modo el deseo en Proust estructura un conocimiento del mundo a través del arte. Partiendo de la relación que este autor ha tenido con diversos críticos -Bataille, Barthes, Blanchot, Deleuze, Eribon, etc.- y de las múltiples posibilidades que Proust otorga para leerlo en clave biográfica, como así también en clave discursiva, nuestro trabajo se propone analizar cómo el deseo, más que un vínculo con los objetos, representa en el mundo de À la recherche du temps perdu un vínculo inmanente que posibilita entenderlo como una teoría capaz de aplicarse al conocimiento por medio de lo estético.

Palabras clave: Proust, Deseo, Estética, Teoría, Subjetividad.
Summary: The present work analyzes how desire in Proust structures a knowledge of the world through art. Starting from the relationship that this author has had with various critics Bataille, Barthes, Blanchot, Deleuze, Eribon, etc.-, and the multiple possibilities that Proust grants to read his work in biographical code as well as in discursive code, our work proposes to analyze how desire, rather than a link with objects, represents an immanent link in the world of $\grave{A}$ la recherche du temps perdu that makes it possible to understand desire as a theory capable of applying itself to knowledge through aesthetics.

Keywords: Proust, Desire, Aesthetics, Theory, Subjectivity. 
¿Qué deseo es el que persigue Proust a lo largo de su búsqueda del tiempo perdido? ¿Qué deseo es el que puede hacer de ese tiempo la forma de una obra que retrata la fuga de su presente y a su autor en el hundimiento de su encierro? ¿Se trata de un deseo que desea nada más que lo vulgar y lo sublime de un bizcochito embebido en té como retorno del pasado? ¿O más bien se trata de un deseo que presiente y ve casi por azar, tras una distracción, en unos mosaicos venecianos llevados por delante- que el tiempo recuperado, ese tiempo que obsesiona a Proust, no es en verdad más que el tiempo de un mundo que ha desaparecido y que, por más que se lo escriba, por más que se lo vuelva la forma última de la literatura, no encuentra ya más nada que desear? ¿Por qué no pensar que los espinos blancos de Combray, el pasaje musical de una sonata, el beso de buenas noches que una madre posterga, los celos o los secretos de amor entre muchachas es lo que alimenta, da cuerpo, sustento y gravedad al deseo oculto detrás de las largas frases que, cual decorados de un teatro de la memoria, se levantan como naves de una catedral y al instante, con el mismo ritmo con que las olas en Balbec bañan las playas por donde pasean las muchachas en flor, caen y se borran? ¿Se trata entonces de un deseo que lleva todo fenómeno del mundo al tiempo final de la escritura? ¿Es ese deseo -escribir, solo escribir y nada más que escribir- lo que conduce hacia la búsqueda? ¿O es la búsqueda -como un no poder estar sin escribir- lo que finalmente lleva a leer en el deseo un camino 
que, como tal, y etimológicamente hablando, no es más que un deseo de teoría?

Ningún otro autor ha llamado tanto la atención de la crítica literaria como lo ha hecho Proust, que en sus inicios fue negado por André Gide y Anatole France, pero también, en la posteridad, fue recuperado por Maurice Blanchot, George Bataille, Gilles Deleuze, Julia Kristeva, Roland Barthes o Didier Eribon. Así, una y otra vez, en torno a él la crítica ha reiterado las mismas preguntas, ¿qué tipo de deseo le interesó a Proust? ¿Qué deseo alimentó la desproporción de su escritura? Lo cierto es que la naturaleza enigmática de ese deseo supone una fascinación o una afinidad, cierta influencia o cierta inspiración que ha hecho de él un objeto y una experiencia para la crítica. Aún más, como una postrimería romántica podríamos decir que la obra de Proust cristaliza aquel viejo postulado de una autonomía crítica en la poesía, ya que su escritura busca resaltar "el criterio de una precisa construcción inmanente de la obra misma" (Benjamin, 2000, p. 108). Así, pensando el deseo como un objeto, Proust llega en realidad a la inmanencia misma del deseo, llega a hacer de él un procedimiento antes que una cosa; en fin, llega a la experiencia del deseo, a lo que permite conocer el mundo solo en tanto esa experiencia se vuelve intimidad de la obra. Proust logra que el deseo renuncie a su exterioridad, aun cuando en ella este se origina y encuentra sus objetos; a partir de ahí el deseo será entonces deseo de escritura. Todo Proust es el comienzo y el fin de una teoría del deseo. Tal teoría está presente en $\dot{A}$ la recherche $d u$ temps perdu y permite adentrase en lo que verdaderamente interesa: el conocimiento del mundo, del que 
ha sido, del que desaparece, del mundo en el cual Proust se sustrae en largas frases tejidas con formas, nombres y signos. ${ }^{1}$ Por ello mismo, su obra, más allá de la orientación decreciente que la caracteriza -tanto literaria, pues escribió solo un libro, pero también biográfica, pues se retiró hacia el revés del encierro-, es el espejo adonde las imágenes de un tiempo singular, como señala Blanchot, se yerguen desde la oscuridad y se orientan hacia un lenguaje hecho para la literatura; un lenguaje que, indudablemente, es el relato de un mundo en retirada, pero también el relato de la literatura avanzando en el territorio dejado por ese retiro. ${ }^{2}$ Lo que sorprende es que ese territorio dejado por el retiro es el territorio de la escritura. $\mathrm{Ni}$ bien esta comienza, Proust en algún punto sabe que debe abandonar lo continuo en procura de responder a la densidad

\footnotetext{
1 Habría que señalar que, del mismo modo que los nombres poseen un espesor de significación, el deseo también lo tiene y, por lo tanto, es otra forma de "ilusión y decepción" en el aprendizaje proustiano que, según Barthes, consiste en atravesar largos y variados caminos, los cuales conducen a la esencia de las cosas, para lo cual solo hay que "adentrarse poco a poco en las significaciones del nombre [ya que el nombre/el deseo] es iniciarse en el mundo, es aprender a descifrar sus esencias" (Barthes, 2006, pp. 177, 187 y 189).

2 Según Blanchot, la orientación seguida por Proust se basa en una transformación del tiempo que solo puede llevarse adelante en tanto esta es una experiencia de verdad y sentido, una búsqueda que descubre una vocación de escritura, que asigna a esa experiencia un lenguaje, un lugar en la superposición del tiempo del mundo y el tiempo del relato:
}

Resulta que Proust, debido a una fascinante confusión, extrae de las singularidades del tiempo peculiar del relato, singularidades que penetran en su vida, los recursos que le permiten también salvar el tiempo real (...) Asimismo, Proust, al hablar del tiempo y vivir lo que habla, y al no poder hablar sino a través de ese tiempo distinto que es en él la palabra, mezcla, mezcolanza a veces intencional, a veces onírica, todas las posibilidades, todas las contradicciones, todas las maneras según las cuales el tiempo se hace tiempo. Así termina por vivir la manera del tiempo del relato y encuentra entonces en su vida las simultaneidades mágicas que le permiten contarla o, por lo menos, reconocer en ella el movimiento de transformación mediante el cual se orienta hacia la obra y hacia el tiempo de la obra en que ella se cumplirá" (Blanchot, 1987, pp. 17 y 18). 
de la frase, la concentración, la búsqueda de lo que ya no está y solo el lenguaje traerá de vuelta, no tanto como un recuerdo, sino más bien como un despliegue de sus transformaciones. La estructura de lo cambiante es la enunciación imposible buscada por la Recherche, así como el silencio, lo inmutable, esa elevación en el mundo de lo que está por fuera del mundo, lo es en las catedrales que Marcel, el protagonista de los siete volúmenes, interroga insistentemente. Sin embargo, como señala Deleuze, esa misma obra que lo transforma todo o que se empecina en hacer de la transformación un protagonista fantasma es en realidad el lugar donde se pueden leer los signos de una máquina literaria que da cuenta de una experiencia que debe entenderse como aprendizaje del sentido antes que como aprendizaje del mundo. El arte es más profundo que el pasado, su mismísima dificultad es más intensa que la resistencia de lo perdido en su lugar inaccesible. Leída en un sentido reminiscente la Recherche se vuelve un argumento monstruoso; sin embargo, la fascinación empírica de Proust puede trascender lo ontológico y lo estético, puede hacer de la transformación del deseo la buena intención de una ley para el deleite de su encierro. ${ }^{3}$ Ya sea en el intento de hacer del tiempo

${ }^{3}$ El idealismo de Proust fascina por su estructuración, por su apetencia de una religión del arte, pero también de una epistemología de los fenómenos como todo lo que tenga que ver con lo mundano o con el amor mismo. En esta intermitencia él se permite contrarrestar la distancia tomada respecto del mundo con la proximidad en la cual se sabe autor de una forma única e irrepetible que, como bien se sabe, costará no solo años y encierro, sino también una vida. Pero esto es parte del precio pagado a la aprensión de los signos del arte, es el camino que se emprende desde la materialidad a la disolución como forma última, pues, como señala Deleuze, se trata de un aprendizaje estético de lo esencial:

Ahora bien, el mundo del Arte es el último mundo de los signos; y estos signos, como desmaterializados, encuentran su sentido en una esencia ideal. Desde entonces, el mundo revelado del arte reacciona sobre todos los demás, y principalmente sobre los 
su materia, una imagen que se corresponda con su experiencia, o de estructurar un conocimiento del mundo que se cristalice en formas nunca pensadas por la literatura, es decir, al unir experiencia y composición, al emplear la propia vida y al perderla, Proust hizo del deseo mismo un procedimiento que se volvió la distinción de su literatura. Omnipresente el deseo, cabe preguntarse entonces ¿es una experiencia solitaria impuesta por la escritura antes que por el simple desear? ¿Se puede desear enfermo y lejos del mundo, en la oscuridad de una habitación aislada hasta del más mínimo ruido en el número 102 del Bulevar Haussmann?

\section{II}

Más allá de lo que la crítica hiciera por Proust, es posible leer en él una verdadera lección de egotismo; es posible leer el devenir de una sensibilidad que se vuelve inteligencia y también la asombrosa aventura de una frecuencia mundana que termina siendo saber de vida. Entre la experiencia vuelta obra y la cercanía del mundo como un enigma Proust despliega la presencia omnipresente de un Yo que apenas aparece una vez, intermitente y casi como al pasar, y que solo es nombrado en los escasos alcances del nombre Marcel; pero que aun así señala la subjetividad como un tema de afectos superpuestos,

signos sensibles. Los integra, los colorea de un sentido estético y penetra en la opacidad que todavía conservan. Entonces comprendemos que los signos sensibles ya remitían a una esencia ideal que se encarnaba en su sentido material [...] por ello todos los signos convergen en el arte; todos los aprendizajes, por las vías más diversas, son ya aprendizajes inconscientes del arte mismo (Deleuze, 1995, pp. 22 y 23). 
de figuras desplegándose a lo largo de lo escrito y conducidas por un fantasma, por el impulso de una huida. Proust puede ser leído entonces bajo la suerte de una teoría del deseo o bajo la fatalidad reductora de la correspondencia biográfica; ${ }^{4}$ pero, en definitiva, siempre se trata de una escritura de largo aliento que, de una u otra forma, por negación o por disimulo, se reduce a la transformación de ese yo en deseo. La pregunta sería entonces cómo es posible esto, qué se requiere para ello, de qué modo avizorar el momento más propicio para esa transformación.

El deseo puede transformarse si encuentra en la vida la posibilidad de ser tal, pues requiere de una cima de lo particular, una especie de momento de decisión o momento de verdad. Sin ello no hay nada. Resulta entonces imposible pensar $\grave{A}$ la recherche du temps perdu sin la vida por detrás; y cuando nos referimos a la vida nos referimos no a lo estrictamente biográfico, a lo que en definitiva sabemos de Proust, sino a lo que podríamos entender como lo imposible de narrar para Proust o para cualquier otro sujeto que hace de la vida su tema. Una vida es eso, su imposibilidad tanto de llevarla adelante como de adjuntarle una forma; pero también la negativa a abandonarla como intratable, a desestimarla por su creciente complejidad. No se puede vivir por un lado y contar por otro, hay que vivir para contarlo; hay que vivir contando lo que falta,

\footnotetext{
4 A esto Barthes lo designa Marcelismo, y cabe aclarar que no es más que el interés creciente en "su vida, sus amigos, sus excentricidades" al momento de entender la irrupción de "la vida como obra" en el universo de Proust y, por tanto, comprender también cómo en un sujeto lo mundano -que deviene intensidad biográfica- y lo sublime -que no es más que aplicación a la hora de contar el origen de un mundohacen a una subjetividad única (Barthes, 2005, pp. 391 y 278).
} 
lo que se perdió y aquello que en lo perdido otra vez se pierde. Por fatalidad se vive, pero por voluntad de distracción -como señala Nietzsche- con esa vida se hace arte para olvidar justamente la fatalidad de tener que vivir nada más y nada menos que con uno, con el disimulo de lo que se es. ${ }^{5}$ Por eso para Proust la vida está llena de momentos particulares, de cimas en las cuales el sujeto entiende que puede hablar sobre sí. Pero también, solo en tanto lo particular alcanza su mayor altura, la vida se transforma, se vuelve otra cosa y, por supuesto, es allí donde hay que leer el origen de una forma para la vida.

En Proust la muerte de la madre es ese particular que puede transformar una vida; en ello se cifra el fin de un mundo, pero también allí comienza el mundo de la escritura. ${ }^{6}$ Antes de esa

${ }^{5}$ La concepción estética de Nietzsche se funda justamente en las transformaciones acontecidas en el origen de la tragedia, las que participan en su inmediatez de la vida y luego derivan hacia lo estético; por lo tanto, podríamos pensar que lo estético en sí no es más que una estructuración de ese trauma de origen que, una y otra vez, nos recuerda que ya no participamos del mundo, que solo accedemos a él por medio de la reflexividad del arte, que lo estético era lo poético en sí y lo poético era la aplicación a una forma, operación que Proust llevará hasta el extremo mismo de la forma:

"Lo estético es, en el fondo, un fenómeno sencillo: es poeta el que posee la facultad de ver sin cesar un juego viviente y vivir rodeado por multitud de espíritus; es dramaturgo el que siente un impulso irresistible a metamorfosearse él mismo y a vivir y obrar por medio de otros cuerpos y otras almas" (Nietzsche, 2009, p. 69).

${ }^{6}$ Acongojado por la muerte de su madre, Barthes acude a Proust para incentivar la huida del propio deseo, dejando así atrás el estado de acedia que lo atormenta, pensando de este modo un necesario camino medio de su vida, un antes y un después capaz de medirse por la potencia de un afecto perdido. Su cima de lo singular en este caso se transforma en un "activo de dolor", el cual no hace más que superponer la propia madre a la madre de Proust, y el propio deseo al deseo de aquel. Si para Barthes entonces "la historia contada por Proust es la del Escribir", la historia que él debería contar es la del poder vivir de otro modo, la de una huida que simula abandonar cierto paisaje de la melancolía. En su último seminario titulado La preparación de la novela, que por cierto no es más que una serie de fragmentos dispuestos para narrar la imposibilidad de acceder a un todo, y que por eso mismo puede emplearse como excusa para desplegar el propio 


\section{muerte Proust se pierde en la vida de los salones, se equivoca y se desgasta en los proyectos literarios que emprende. Se bate a duelo con quien lo acusa de homosexual, y es tratado por Gide en su correspondencia como alguien no publicable, y en su diario como la marica especialista en el disimulo y el}

deseo, el paisaje de la melancolía se vuelve ciertamente una afección, pues da cuenta del animus del profesor Barthes que ya no se reconoce en esa figura, pero que, a la vez, aun así se sabe potencialmente otra cosa: "Tristeza, cierto tedio, lo mismo, ininterrumpido (desde un duelo reciente) y que se refleja en todo lo que hago, lo que pienso (falta de investidura). Regreso, departamento vacío; ese momento difícil: la tarde. Solo, triste; reflexiono con bastante intensidad. Eclosión de una idea: algo así como la conversión «literaria», son estas dos palabras antiguas las que vienen a mi mente: entrar en literatura, en escritura; escribir como si no lo hubiera hecho jamás: hacer solamente eso". En este recorte de la intimidad del profesor acongojado por su rutina se puede ver al crítico imbuido por el deseo de verse arrastrado a hacer como si fuera tan solo un sujeto que desea escribir una novela, suerte de revés de todo lo vivido por medio de la escritura hasta el momento. Renunciando al objeto, y a las preguntas que giran a su alrededor, por caso: ¿qué es una novela?, ¿qué es un autor?, el último Barthes abraza la experiencia de lo imaginario y se dispone a plantear nuevas preguntas que esta vez gravitan alrededor de nuevos interrogantes, por caso: ¿cómo se escribe una novela?, ¿en qué momento lo fragmentario se vuelve un todo?, ¿cuál es el paisaje de la imaginación que acompaña al escritor en momentos de verdad que son verdaderos momentos en los que aparece lo intratable de la vida? Acosado por Proust, por su mundo, el Marcelismo inventado, acosado por ese pasado más seductor que el presente desdeñoso, pero también guiado por este, quien pasa a ser una suerte de Virgilio moderno, Barthes se orienta en el medio del camino de su vida hacia la reforma de esa vida: de crítico a novelista - pero no dejando en claro si alguna vez escribirá esa novela-. Lo que podríamos denominar el enigma Proust, que tal vez consiste en cuajar y a la vez escindir la correspondencia vidaobra, lleva al crítico entonces a habitar en la nebulosa biográfica donde tanto las fotos del mundo de Proust, proyecto de un último seminario, se entremezclan con las fotos de la intimidad del propio Barthes, último libro pensado para esa tan añorada ciencia del sujeto. Es indudable entonces que el último Barthes que prefiere dejar hablar al yo es el Barthes que no duda en afirmar que "no se consigue nunca hablar de lo que se ama". La imposibilidad del amor es lo que lo vuelve intratable, y en tanto que es intratable, el amor es el tema por antonomasia de la literatura que le interesa. Proust amado por Barthes es la fórmula que podría orientarnos en esa relación entre deseo y teoría, en la transformación del yo en deseo y en la detección de toda cima de lo particular. Pero el principal interés de amar radica en que lo que se ama no es ni más ni menos que un sujeto; algo que, por encima de lo biográfico, se adensa en la dimensión que lo biográfico tiene de intratable. En Barthes, y de la mano de Proust, el sujeto regresa para señalar justamente que decir yo es traer a la literatura "la complejidad de la red de enunciación”, del mismo modo que para Proust lo complejo fascinaba (Barthes, 2006, pp. 41, 157, 159 y 277). 
camuflaje..$^{7}$ Muerta la madre, la cima de lo singular se abre hacia un paisaje familiar pero remoto, que habrá que ir a buscar, pero por medio de un camino que sea la medida del propio deseo.

En La literatura y el mal George Bataille señaló que este hecho es fundamental para la Recherche tanto por fuera del relato como en su interior, y más aún, teniendo en cuenta que Proust padeció "la pasión de la verdad" (Bataille, 1956, p. 101). Muerta entonces la madre, lo que irrumpe es la voluptuosidad del deseo, su transgresión como escritura, como obra que demanda una vida; sin embargo, más que la transgresión lo que importa a la voluptuosidad es la tensión que por un lado permitirá que Albertine, la que desaparece doblemente, se superponga a la figura de Alfred Agostinelli, el chofer amado por Proust; y también que los amores de Proust, que no se pueden nombrar, se orienten hacia el pliegue de lo oculto, haciendo así de la obra un sacrilegio al nombre de la madre en

\footnotetext{
${ }^{7}$ La relación entre Gide y Proust se funda en el malentendido; desde la lectura superficial de una primera versión de Por el camino de Swann, donde Gide encuentra desagradable lo largo de la frase, hasta ciertos detalles estructurales de lo mundano: como costumbres alimenticias y errores fisonómicos en el interior de la novela que apenas si es revisada. Sin embargo, para 1912 cuando Proust envía su versión a la Nouvelle Revue Française, cierta imagen ya hace a Proust el narrador de un mundo pronto a desaparecer, como en 1914 Gide se lo confiesa en la siguiente carta: "Haber rechazado este libro será el más grave error de la NRF; y además (pues tengo la vergüenza de ser en gran medida el responsable de ello) uno de los pesares, de los remordimientos más mortificantes de mi vida. Sin duda, creo que debe verse en esto un hado implacable, porque sería explicar muy insuficientemente mi error decir que me había hecho de usted una imagen a partir de algunos encuentros en «el mundo», que se remontan a casi veinte años. Para mí, usted seguía siendo aquel que frecuentaba la casa de las señoras $\mathrm{X}$ y Z, el que escribe en Le Figaro... Creía que usted estaba -¿me atreveré a confesárselo?- «por el camino de los Verdurin»" (Proust, 1999, pp. 17 y 18). La confesión restante, sobre el disimulo y el camuflaje, Gide se la reserva para el Diario, como bien lo señala Kristeva (2005, p. 185).
} 
la inmanencia de lo simbólico. Es evidente entonces que al deseo le encanta disfrazarse, perderse detrás de nombres, máscaras, plumas, gestos, muecas y sonrisas; volutas de un vértigo compositivo que en su conjunto sirven para otorgarle a lo contado vigor significativo, profundidad semántica. Como señalara Lezama Lima en un verso ya muy famoso de su poema "Llamado del deseoso", justamente "deseoso es aquel que huye de su madre [...] Deseoso es dejar de ver a su madre". 8 El deseo no puede ser más que huida entonces, marcha, camino, teoría, la intuición de una forma. La Recherche de Proust es la potencia del deseo como huida, la exterioridad misma del mundo encauzada por la teoría que le otorga así a la vida una pasión por la verdad. Por lo tanto, La Recherche es un aprendizaje en soledad de las formas en las que se oculta y se devela el deseo.

\section{III}

Proust entendía el amor -tal vez lo más intratable de la vida- como la búsqueda de un saber absoluto del otro. De esa obsesión provienen los problemas que el amor trae aparejado. Por un lado, un deseo de saber que es guiado por la atracción, un aprendizaje de los celos que indica la finitud de toda afección; pero también, por otro lado, una decepción que,

8 "La madre es fría y está cumplida. / Si es por la muerte, su peso es doble y ya no nos suelta. / No es por las puertas donde se asoma nuestro abandono. / Es por un claro donde la madre sigue marchando, pero ya no nos sigue. / Es por un claro, allí se ciega y bien nos deja. / Ay del que no marcha esa marcha donde la madre ya no le sigue, ay" (Lezama Lima, 1970, pp. 95 y 96).

$N^{\circ} 13$. Segundo Semestre de 2020 
como tal, conduce al verdadero aprendizaje por medio del arte. Solo así la literatura al volverse reflexiva, con la posibilidad de escritura que el tiempo recobrado otorga, posibilitará enmendar las distracciones sentimentales de una vida. El deseo se enfrenta entonces a lo intratable: el amor que también puede ser lo prosaico del mundo, la simple y paralizante fascinación de lo vulgar; pero en verdad el amor no es más que un comienzo. ${ }^{9}$ La aventura del sujeto que desea consiste en traspasar ese desencanto propio de la impasibilidad material, superar la apatía que envuelve a los fenómenos y encontrar una verdad invisible en el tiempo que aún no es reflexivo, el tiempo que aún no se puede recuperar, pero que emite impresiones sobre el sujeto; el tiempo que simplemente se pierde para otorgar el espesor sentimental que la vida requiere. Desear la escritura como forma para una vida es preparase para la decepción, para el retiro del mundo, pero también es preparase para un mundo por venir. Catherine Millot (1993) señala que la vocación de escritor en Proust se mide en un principio ante la decepción que asalta al deseo cuando quiere atrapar esas impresiones, cuando busca reproducirlas en un lenguaje en donde no hay correspondencia entre palabras y cosas. El deseo entonces mira lo que no puede ser en el mundo no solo por correspondencia, sino también por expresión, por ausencia, por sustracción al momento de origen; y, por lo tanto, el

\footnotetext{
${ }^{9}$ Deleuze ha establecido un trayecto que va del amor hacia al arte, del signo material al signo sensible y que, como tal, requiere de un sujeto por demás activo. En ese itinerario lo que se define es la implicancia del aprendizaje, los alcances que reviste toda acción, ya que "llenamos la decepción del objeto con la compensación del sujeto"; sin lugar a dudas, afrontar los signos del amor que conducen a los signos sensibles del arte implica que en toda interpretación "sustituimos los valores inteligibles objetivos por un juego subjetivo de asociación de ideas" (Deleuze, 1995, p. 47).
} 
escritor que Proust quiere ser solo tiene una serie de fragmentos, huellas, trazos que lo llevan a intuir una totalidad; solo tiene jeroglíficos a interpretar para de este modo conferirles una verdad. Aun así, al final con todo habrá confeccionado una presencia real, el equivalente a lo que en el lenguaje estaba sustraído; la aventura de escribir será entonces la compensación y a la vez la tumba que mide el tiempo del encierro en tiempo recobrado, pero esta vez, lejos de toda contingencia, bajo la forma de una obra, el equivalente a lo que falta con el cual el escritor se orienta en las indagaciones del tiempo. Como señala Millot los objetos en Proust siempre fueron portadores de un mundo, descubrir dicha característica, separarlos del resto, dejarse afectar por ellos -en las catedrales ver una estructura, en un bizcochito el verano de la infanciaes aventurar la posibilidad de escribir ese mundo confiándolo todo a la capacidad de invención que el deseo pone en práctica: "El artista es aquel que, desprendiéndose de la fascinación ejercida por el misterio del objeto, produce la conversión que consiste en buscar la clave de ello en sí mismo, es decir, inventar su equivalente" (Millot, 1993, p. 63).

Sin embargo, lo que sorprende es que muchas veces esa presencia real proviene de sus instantes de mundanidad, de su pasar de los salones bulliciosos a la soledad y el silencio de la habitación de Proust. También por momentos el impulso hacia lo real proviene de saber transformar chismes en revelaciones; muchachos amados en muchachitas deseadas; en hacer de la intensa vida social un deseo que llega hasta el corazón mismo del mal, oculto detrás de contraseñas que deben leerse como figuras de una danza. Proust ha hecho del mundo de los 
salones, de los paseos por bulevares, de los prostíbulos de Sodoma y Gomorra, de los balnearios y hasta de la vida de provincia un campo para la teoría de lo que puede ser visto y lo que puede aparecer como oculto. En esa oscilación de lo visible y lo invisible el deseo se transfigura detrás de una u otra posibilidad, hace del paisaje un llamado a la observación, de las superficies una imantación que convoca a la aplicación microscópica de la mirada. Por ejemplo, en $A$ l'ombre des jeunes filles en fleurs, la propia Albertine aparece en el revuelo juvenil de lo que el autor define como una bandada de gaviotas, una mancha que avanza por el muelle de Balbec, el flujo armonioso de una belleza colectiva adonde solo se lee el trazo indistinto de los cuerpos que, por cierto, contrastan con la rutina somnolienta de la aristocracia de fines de siglo XIX. No son entonces más que muchachas gritando, corriendo, llevándose todo por delante, agitadas a causa de saber que serán observadas; sin embargo, son una singularidad que se desplaza entre el sopor, la pasividad del verano y la percepción que de ellas tiene un cuerpo enfermo, una salud frágil, la vitalidad del recluso que se transparenta en la voz del narrador. El fauno despierta de su siesta y mira a su alrededor, levanta la cabeza y persigue una música. Entre la bandada de pájaros y el ramillete de flores con que Proust las compara, o, mejor dicho, bajo la forma en la cual se vuelven visibles para él, Albertine y sus amigas se hunden en la sombra del propio deseo que espera ser descubierto, se hunden en la complejidad que busca emerger y desplegarse. Ellas son Balbec, sus sensaciones, sus reminiscencias, el mundo por descubrir. Sin nada que se le parezca, el grupo de chicas no solo contrasta con el paisaje del 
balneario por su vitalidad apenas delineada, sino también porque se vuelve centro de atención, el lugar adonde la mirada se posa: "Aunque cada una tenía un tipo distinto del de las otras, todas tenían belleza; pero, a decir verdad, hacía tan poco que las miraba fijamente que todavía no había podido individualizar a ninguna (Proust, 2007, p. 449). Individualizar es la acción propia del deseo para alcanzar la distinción, que no es un discernimiento, sino más bien un reconocimiento entre aquellos que comparten una verdad del corazón. Por medio de la distinción, lo bello puede discernirse desde ese perfil propio de la forma indistinta hasta llegar así a ser un sustrato profundo por descubrir. Desde la pertenencia de clase, hasta los lineamientos de cierta gracia en el trato, pasando por el ardor de la juventud, el narrador que las observa se pregunta por la existencia de un signo que las distinga, que explique su fascinación, se pregunta por el vínculo invisible que las recorta del resto de los mortales. Pero, en realidad, la distinción buscada se orienta más hacia el flagelo de la posesión antes que hacia una respuesta que satisfaga.

Proust también señala que "el amor más exclusivo por una persona es siempre el amor a otra cosa” (Proust, 2007, p. 500). ¿Qué es en este caso esa otra cosa? Una vez recortada Albertine del grupo de pájaros que conforma con sus amigas, de ella solo queda el enigma de su constante cambio. De este modo, del carácter implacable a la intimidación, del encanto de su aparición a la frecuencia cotidiana, y de las formas armónicas de un conjunto de cuerpos a los detalles de una fisonomía particular: orejas, facciones en los ángulos de la cara, un corte de cabello y un peinado, y hasta la presencia de un 
lunar oscilante, lo que sobresale en todo ello es la fugacidad de ese objeto de deseo, su constante ocultamiento hasta la desaparición, la intermitencia de lo que está siempre expuesto a extinguirse. Albertine es distinguida por el deseo porque todo lo que hay en ella se compone del impulso de la huida, de la potencial desaparición. Así como en cada instante algo del mundo que nos rodea se modifica, en cada gesto y en cada cuerpo el tiempo también se transforma o se pierde, razón por la cual el libro de Proust es el libro de las metamorfosis en el objeto de deseo, pero también, del mismísimo deseo del narrador. ¿Se desea siempre lo mismo si nada permanece estable? ¿Es lo mismo uno que otro objeto perdido, vuelto a encontrar y de nuevo otra vez perdido en la galería que conforman los rostros que se aman a lo largo del tiempo? Sometido a ese vértigo lo otro que el amor trae consigo es la diferencia sobre el amor mismo; ya no se trata de un desenfreno y una armonía que se contrapesan en el mismo amante, ese modelo del amor pensado por Dante o Petrarca; el amor de Proust es más bien un amor desesperado por la posesión, un amor que no se conforma con el enigma de la distinción, sino que sádicamente busca su goce en la imposibilidad de saberse dueño de una vida entera:

Yo sabía que no podía poseer a aquella joven ciclista si no poseía también lo que había en sus ojos. Y era por consiguiente su vida entera lo que me inspiraba deseos: un deseo doloroso, porque lo sentía irrealizable, pero embriagador, porque lo que había sido hasta ese momento mi vida, había dejado de ser mi vida total, y no era más que una pequeña parte del espacio tendido ante mí que yo ardía por cubrir, y que estaba hecho con la vida de aquellas muchachas, y me ofrecía esa prolongación, esa 
multiplicación posible de uno mismo que es la dicha (Proust, 2007, p. 445).

Duplicada en los otros, oculta en los secretos de los otros, pero pronta a develar los propios secretos, la vida dichosa que el narrador aspira a conquistar se volverá imposible de conocer si no se tiene eso que trastorna al deseo; y lo que trastorna al deseo es el secreto mismo del deseo, el origen o causa de por qué se desea lo que se desea; pero también, el vértigo siempre presente de desear otra cosa que como tal permanece oculta.

\section{IV}

Proust retrata a la perfección estos primeros años del deseo que transcurren entre Combray, los Campos Elíseos y Balbec. El paso de la infancia a la adolescencia, las afecciones que genera todo lo que rodea a Marcel, y ciertas motivaciones que lo inician en el mundo de las correspondencias y los reveses del amor hacen al espesor de la experiencia que se recupera. Sin embargo, hay un punto en el cual deseo e inocencia se separan bruscamente; hay un punto en el cual el mundo del pasado deja ver la sombra del deseo que anida en la sombra de la adolescencia. Por ejemplo, a la fascinación que el deseo produce en el narrador frente a la bandada de chicas le siguen los espejismos de una pertenencia mítica; al entusiasmo de la Albertine-pájaro, inocente, siempre escurridiza y vital le sigue la decepción de la Albertine-burguesa, frívola, esnob y distante hasta la desaparición; en definitiva, a ciertos códigos del gusto de una época y una clase de la que Proust es exponente en lo 
apreciable y en lo oculto, el deseo hace que le corresponda la perturbación que produce lo indefinido, lo afectado, lo invertido en el sentido de la orientación esperable; en pocas palabras, el deseo en Proust se corresponde con un impresionismo del Mal.

Parte de esos primeros años del deseo transcurren en torno al descubrimiento del arte, pues solo él puede entregar ese discernimiento de lo aparente que busca elevarse a la pasión de la verdad. De este modo Balbec no solo es el encuentro con Albertine, sino también el descubrimiento de Elstir, suerte de pintor que hace de la percepción sensible un lenguaje para el libro de las metamorfosis. En sus cuadros el narrador descubre que aquello que en la vida posee un nombre, una designación por demás convencional, aquello que por cierto se encuentra en un extremo de nuestra atención, en los motivos de Elstir se ve representado bajo otro nombre, adquiere una estructura que une los puntos extremos del entendimiento, tal vez lo que separamos como opuestos encontrados, pero que solo así, en una unidad superior, pueden convivir bajo la forma que el arte les propone. Todas las apariencias del mundo que Proust busca recuperar y que intuye dispersas -los objetos, los paisajes, los sexos- en verdad se revelan en las metáforas que las recubren. La metáfora, que Elstir practica no solo como un recurso técnico sino también como un modo de entender aquello que lo rodea, es la potencia de su mirada; lo que llevado al terreno de la literatura podría asemejarse al postulado de Flaubert: "el estilo es un modo absoluto de ver las cosas" (2017, p. 65). Así, un simple motivo marino pintado por él adquiere la relevancia de su forma absoluta: el mar superpuesto a la franja de la costa 
y los bordes de la playa fundiéndose en la lejanía de las olas, sin saber dónde está una y dónde está el otro, pues todo es sensación diversa, impresa, fragmentaria y a la vez unívoca en la percepción:

Una de las metáforas más frecuentes en las marinas que tenía a su lado en ese momento, era justamente la que, al comparar la tierra con el mar, suprimía entre ellas toda separación. Era esa comparación, tácita e incesantemente repetida en una misma tela, la que introducía aquella multiforme y poderosa unidad, causa a veces no percibida claramente por ellos, del entusiasmo que excitaba en algunos admiradores la pintura de Elstir (Proust, 2007, p. 508).

Del mismo modo las frases de Proust son pequeños cuadros, superposiciones de color, territorios que se tocan; ellas comienzan en la seguridad de un objeto aparente, una sensación común; pero ni bien creemos llegar al final, en verdad todo está en el justo medio, allí adonde lo indistinto del comienzo y del final se unen dejando de lado lo que tienen de opuestos para poder hablar de otra cosa que emerge gracias al borramiento mismo de esos extremos. Manierismo, afección, impostación o amaneramiento -lo que Deleuze define como lo propio del estilo de Proust: la complicación-; ${ }^{10}$ de este modo y de otros tantos- fue calificada su escritura al simplemente apegarse a la certeza de lo ambiguo, a un nuevo modo de mirar el mundo. Al igual entonces que la orientación retórica de la frase, o que la composición pictórica del motivo, el deseo antes

10 "El estilo, para espiritualizar la materia y hacerla adecuada a la esencia, reproduce la inestable oposición, la complicación original, la lucha y el cambio de los elementos primordiales que constituían la propia esencia" (Deleuze, 1995, p. 60).

$N^{\circ} 13$. Segundo Semestre de 2020 
que discernir o clasificar cualquier objeto produce un acercamiento y un alejamiento respecto a este: primero Albertine es objeto de fascinación y luego simple materia apática, Albertine como prisionera y luego como objeto desaparecido.

Para Proust, entonces, el arte antes que representaciones produce develamientos, despliegues de un revés secreto, una suerte de acontecimiento similar a evidenciar la desnudez en lo oculto. No solo se trata de recordar; mirar es también el camino que conduce a la búsqueda, al descubrir. En el estudio de Elstir, el joven Marcel se detiene ante un cuadro casi olvidado, una obra menor y de otro periodo, que el propio pintor ha ocultado entre tantas. Se trata de un retrato de una mujer joven, para nada bonita, poco agraciada, pero sí de un tipo curioso que según el narrador al detenerse frente a ella "produjo esa clase particular de encantamiento" (Proust, 2007, p. 518). Rodeada de flores, en una pose por demás reconocible, y vestida justamente con el desacuerdo de la moda -lo que prefigura el disfraz que la recubre, la joven actriz de Elstir llama la atención justamente por esa vacilación que el adolescente Marcel experimenta ante "el sexo del modelo" (Proust, 2007, p. 519); pero también llama la atención por cómo su autor "se había aferrado a aquellos rasgos de ambigüedad como a un elemento estético que valía la pena ser puesto de relieve" (Proust, 2007, p. 520). Aun apelando a un joven muchachito como modelo, un artificio propio de la pintura, lo que fascina es esa ambigüedad que el arte, en lugar de ocultar -como la convención pictórica lo quisiera- termina resaltando. Así, el mundo de Proust, aun en los comienzos de 
su aventura estética, es por demás complejo; lo visto está siempre vuelto sobre sí, está oculto y desnudo; el motivo que capta su atención es un jovencito que posa para retratar a una mujer, pero también es una mujer en el fondo de un jovencito, latente, recostada como una planta nocturna que solo en la oscuridad puede vivir, que solo el arte ha podido encontrar, que solo el arte ha desplegado en la voluta misma de los pliegues que la retienen.

Lo ambiguo es otro de los grandes atributos de Proust, no es más que la distancia y la proximidad, a la vez y en simultáneo, de los sexos que en el mundo ni siquiera se reconocen como una leve variación del deseo. Que el disfraz lo evidencie es justamente la tarea del arte, pues el disfraz en vez de recubrir con un velo de distracción resalta y descubre lo que hay de encantador en el modelo: la perturbación de encontrar un sexo en otro, la sorpresa de una vida hallada en lo oculto de la vida; pero, a la vez, también la triste sonrisa del Mal que, como la superposición de la actriz-muchachito, Albertine tendrá para sí. Del mismo modo que la playa y el mar se confunden en el motivo marino, los sexos en Proust también tienen su baile de disfraces, también son momentos de verdad en la impostación de sus máscaras y en el caer de estas:

Por la longitud de las líneas del rostro, el sexo parecía a punto de confesar que era el de una muchacha un poco marimacho, se desvanecía y más lejos se volvía a encontrar, surgiendo más bien la idea de un joven afeminado, vicioso y soñador, después huía de nuevo y seguía siendo inasible (Proust, 2007, p. 520). 
Oculto en el estudio de Elstir, como Proust oculto detrás de su madre, sus personajes, el nombre Marcel, su habitación aislada en el número 102 del Bulevar Haussmann, pero a la vez siempre a la vista de todos y para todos, este retrato que perturba al narrador es más que significativo; los dos sexos que reúne, el de la actriz masculinizada y el del joven afeminado que oculto debajo de la ambigüedad metafórica la representa como marimacho, simbolizan los dos caminos que el deseo tomará luego del fin de la inocencia tras ver Sodoma y Gomorra como orientaciones posibles del deseo. ${ }^{11}$ Pero el deseo que interesa a Proust no tiene tanto que ver con la diferencia en el sexo que descubre; más bien tiene que ver con eso que anida en la mirada del muchachito afeminado -que, por cierto, no es ni Sodoma ni Gomorra, sino la oscilación entre ambos, el verdadero sexo que interesa a Proust-. Hay entonces una expresión para la búsqueda del deseo, hay un modo de hacerlo visible aun en el ocultamiento donde se reviste, y es la ambigüedad, los pliegues con los cuales el amor se vuelve aún más complejo, más intenso, lo que hace a la

${ }^{11}$ La teorización del deseo en Proust, que se vale de toda ambigüedad y de todo movimiento oscilante, se sostiene desde ya en una teorización del sexo que, por cierto, no es unívoca ni mucho menos opositiva, como bien lo señala Didier Eribon, quien, luego de afirmar que "los grandes escritores suelen ser grandes teóricos", despliega un interesante análisis -basado en la relación autor/narrador/personaje- de las teorías del sexo presentes en Proust. Estas, impugnándose unas a otras, se vuelven legibles desde la fascinación y el rechazo, la afirmación y la negación, la aparición y el ocultamiento, y, por supuesto, van mucho más allá de la simple reducción a las figuras de Sodoma y Gomorra, pues ponen en cuestión la relación vida/obra: "Tanta distancia termina sorprendiéndonos: ¿en qué medida y por qué razón ese narrador heterosexual puede ser el vocero de un autor homosexual (Marcel Proust) que ha creado una figura heterosexual (el que dice yo en la novela y cuyo relato da vida a los personajes ) para pensar la homosexualidad y hablar de ella con definiciones de alcance general, que sus personajes homosexuales contradicen de diferentes maneras (Charlus) y a las que, en la vida real, a él mismo le hubiese horrorizado que lo redujeran?” (Eribon, 2017, p. 20). 
constante huida, a su declinar solo en la muerte. Sodoma y Gomorra son entonces lo que sigue en el tiempo por recuperar, son los extremos de la fascinación y el horror como orientaciones de la huida, como origen faltante de ese deseo. Cuando el narrador descubra que Albertine ama a otras muchachas, cuando descubra que huye de él para encontrarse en pensiones con lavanderas pobres, cuando sospeche de los juegos a los que solo tienen acceso sus amigas, experimentará por momentos la fascinación de saber que "cuando se deseaban dos muchachas, se producía como un fenómeno luminoso, una suerte de estela fosforescente que iba de una a la otra" (Proust, 2007, p. 530); pero también experimentará lo insoportable del deseo, esa insatisfacción que lleva al temor, la sospecha, el otro reverso del mundo de Proust: los celos, lo que lleva a enjaular a Albertine, a transformarla en la prisionera que finalmente desaparece:

Claro que Albertine era mucho más prisionera que yo. Y era algo curioso cómo, a través de los muros de su cárcel, el destino que transforma a los seres había podido pasar, cambiarla en su misma esencia, y hacer de la muchacha de Balbec una aburrida y dócil cautiva. Sí, los muros de la cárcel no impidieron que esa influencia pasara; quizás ellos mismos la habían producido. Ya no era la misma Albertine, porque no estaba, como en Balbec, siempre escapando en su bicicleta; inalcanzable debido a la cantidad de playitas en donde iba a dormir a casa de sus amigas, y en donde, por otra parte, sus mentiras hacían más difícil encontrarla (Proust, 2005, p. 372).

Albertine separada del ramillete de muchachas, sustraída a la infinita conversación de los pájaros de la playa, no solo es todas las posibilidades de los caminos del deseo, sino también 
el objeto de posesión que el deseo mismo destruye, marchita, intenta retener atentando contra su huida. Por eso mismo se extingue, y simplemente desaparece.

\section{Referencias bibliográficas}

Bataille, G. (1956). La literatura y el mal. Madrid: Taurus.

Barthes, R. (2005). La preparación de la novela. Buenos Aires: Siglo XXI editores.

Barthes, R. (2006). El grado cero de la escritura seguido de Nuevos ensayos críticos. Buenos Aires: Siglo XXI editores.

Benjamin, W. (2000). El concepto de crítica de arte en el Romanticismo alemán. Barcelona: Península.

Blanchot, M. (1987). El libro que vendrá. Caracas: Monte Ávila Editores.

Deleuze, G. (1995). Proust y los signos. Barcelona: Anagrama.

Eribon D. (2017). Teorías de la literatura. Sistemas del género y veredictos sexuales. Buenos Aires: Waldhuter editores.

Flaubert, G. (2017). Correspondencia teórica. Buenos Aires: Mardulce.

Kristeva, J. (2005). El tiempo sensible: Proust y la experiencia literaria. Buenos Aires: Eudeba.

Lezama Lima, J. (1970). Poesía completa. La Habana: Instituto del libro.

Millot, C. (1993). La vocación del escritor. Buenos Aires: Ariel. 
Nietzsche, F. (2009). El origen de la tragedia. Madrid: Akal.

Proust, M. (1999). Cartas a André Gide. Buenos Aires: Libros Perfil.

Proust, M. (2005). En busca del tiempo perdido. La prisionera. Buenos Aires: Losada.

Proust, M. (2007). En busca del tiempo perdido. A la sombra de las muchachas en flor. Buenos Aires: Losada.

Fecha de recepción: 3o/09/20

Fecha de aceptación: 03/11/20 